\title{
Efficiency on the dynamic adjustment path in a financial market
}

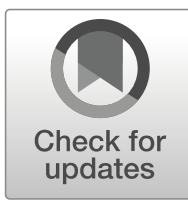

\section{Nasreen Nawaz ${ }^{1}$}

Published online: 17 September 2020

(C) Academy of Economics and Finance 2020

\begin{abstract}
The invisible hand of a perfectly competitive financial market refers to the self-regulating behavior of the market where if each consumer and producer of funds is allowed to freely make their own choices, the market settles at an efficient outcome which is beneficial to all the individual members of the society and hence to the society as a whole. Two wellknown facets of the invisible hand are generally mentioned in the economics and finance literature - the first one is a static picture of a perfectly competitive market, i.e., a competitive market is efficient in an equilibrium; and the second one is that if the competitive market is disturbed from its equilibrium position, in the absence of a market failure and frictions, the market automatically settles at a new efficient equilibrium. This paper takes into account a third facet, i.e., how efficient is a perfectly competitive financial market on the dynamic adjustment path after an economic shock in the absence of all kinds of frictions and interest rate rigidities. We conclude that coordinated actions of economic agents can result in a level of economic efficiency on the dynamic adjustment path which is not achievable by a free market mechanism.
\end{abstract}

Keywords Dynamic efficiency $\cdot$ Adjustment path $\cdot$ Equilibrium $\cdot$ Coordination

JEL Classification D40 D D41 D D50 E32 $\cdot \mathrm{G} 10 \cdot \mathrm{G} 18 \cdot \mathrm{G} 28$

\section{Introduction}

Adam Smith's invisible hand was a clever mechanism for describing how information, idiosyncratic and dispersed among individuals, is accumulated and combined by the market mechanism such that the overall market equilibrium is the same as that would

Electronic supplementary material The online version of this article (https://doi.org/10.1007/s12197-02009523-7) contains supplementary material, which is available to authorized users.

Nasreen Nawaz

nawaznas@msu.edu

1 Federal Board of Revenue, Lahore, Pakistan 
be obtained by an all-knowing social planner. This result is the core principle of all modern Samuelsonion welfare economics. However, the existing literature inadequately addresses the efficiency issue on the dynamic adjustment path of the market after an economic shock before it arrives at a new efficient equilibrium, and rather an adjustment mechanism has never been defined clearly for a perfectly competitive market. There is an inherent limitation in the definition of a perfectly competitive market, which precludes the explanation of movement of the market price after an economic shock. In a perfectly competitive market, all producers are price takers and the prices are perfectly flexible, however, a central question to the discussion is: who changes the price after an economic shock to the market to lead to a new equilibrium? If no one changes the price, then supply will never equalize the demand after an economic shock, resulting in an infinite level of inefficiency. If the producers have to be assumed of changing the price when the market is out of equilibrium, it comes in direct conflict with the assumption of the producers being, "price takers." No other market agent (responsible for the movement of prices) has been defined under the theoretical concept of a perfectly competitive market. In this scenario, it is impossible to provide a theoretical framework for some drifting mechansim for a perfectly competitive market from one equilibrium to the other, as the "price taking," and the "price changing," assumptions contradict each other. A producer cannot be a "price taker," and a "price changer," at the same time, however, with the only assumption of "price taking behavior," the market will logically get stuck in an "out of equilibrium," state for an infinite period of time leading to an infinite level of inefficiency, whereas, the assumption of a "price changer," for a market agent (which is inevitable to explain the change in price from one equilibrium to the other) implies at least a minimal level of market power. This also implies that a perfectly competitive market has to incur some inefficiency after an economic shock, i.e., either it gets stuck in an "out of equilibrium," state (under the agents' price taking assumption) or a market agent changes the price to bring the new equilibrium, in which case, the transition cannot occur free of cost and has to come at the expense of some economic efficiency!

The only way a perfectly competitive market can be efficient during the transition is that the economic shock itself instantly settles the price and quantity from one equilibrium to the other, i.e., the market jumps from one equilibrium to the other as a result of a shock through some magic wand. However, the basis of market mechanism is the self-interest by the economic agents, which acts as a driving force to push the market toward a new equilibrium. When the market is in equilibrium, demand equals supply, however, after an economic shock the market does not instantaneously settle at a new equilibrium, the market forces once again become operative to drive the market and the market follows some adjustment process to move to the new equilibrium. The demand does not equal the supply throughout the adjustment process and there is some efficiency loss before the market settles at an efficient equilibrium. An important question to consider is: Can the market mechanism itself minimize this loss or is there some other mechanism which may improve the efficiency during the adjustment process? In order to address this question, we first need to quantify the efficiency on the dynamic adjustment path, and then compare it with an ideal situation.

Suppose there is only one producer in a market who produces a perishable good and sells it to the consumers living in a community. He sells a quantity exactly equal to the quantity he produces in each time period, and the market stays in equilibrium. If a 
demand shock decreases the demand of his product, some of his production will remain unsold and be wasted by the end of the time period in which the demand shock happened. Assuming that the producer can change the price and the production immediately, had he known the exact pattern of new demand, he would immediately pick the price and the quantity to maximize his profits and clear the market without wasting his production. However, he lacks this information, so he decreases the price based on his best guess about the new demand (based on the quantity of his unsold production), driving the market close to the new equilibrium. If in the next time period, his production is sold out, he will know that the new equilibrium has arrived, however, if a part of his production still remains unsold, he will reduce the price further (and production accordingly) to bring the market closer to the new equilibrium. The market will eventually settle at the new equilibrium after some efficiency loss. The resources wasted by the market mechanism are those which went into the unsold production in each time period during the adjustment process.

In contrast, suppose that after a demand shock, a community coordinator conveys the information about the new demand at various prices to the producer. The producer would immediately pick the profit maximizing, market clearing price and quantity without an efficiency loss. The new equilibrium will be identical in both scenarios, however, coordination seems to improve upon the market mechanism during the adjustment process, through revealing the information of new demand to the producer, which is missing in the market where consumers only care about their self-interest without being bothered about the resources the producer will have to waste as unsold production on account of lack of this information. Therefore, coordination can improve upon the market mechanism in terms of efficiency during the adjustment process, even though the new equilibrium is going to be the same as that would be achieved by the market mechanism.

In the above example, only one producer was assumed just to make the intuition simple and clear, however, the same reasoning goes through for a perfectly competitive market with a large number of buyers and suppliers. In a perfectly competitive market, the exact magnitude of an economic shock is not known to suppliers, and they also lack information on how the consumers are going to respond to a specific shock. They try to gauge the intensity of the shock through the increasing or decreasing size of their inventories and adjust their economic actions accordingly. However, if there is coordination among producers and the consumers, the producers have more information about the new economic scenario and the adjustment to the new equilibrium is smoother and quicker as compared to the adjustment in a free market. It would be too imaginative to believe that there can be such a perfect coordination among all buyers and suppliers which may result into a zero efficiency loss after an economic shock, however, coordination can certainly improve the efficiency during the adjustment process through mutual sharing of information among buyers and suppliers. There might arise issues of coordination costs, however, if the magnitude of shock is large enough and the adjustment process is associated with huge efficiency losses (which if saved could more than compensate the coordination costs) then coordination is superior to a free market, whereas if the magnitude of shock is too small and the coordination costs are comparatively too high, then free market might lead to a more efficient adjustment process. There could also be positive externalities of coordination. These issues need to be discussed separately in future research projects. 
The issue of economic efficiency has much been discussed in the previous literature. The Fundamental Theorems of Welfare Economics are generally stated in a form attributed to Arrow et al. (1952), Arrow and Debreu (1954) and Debreu (1959). Interpreting the conditions under which the First Theorem is true provides the basis of the Market Failure approach. Bator (1958) focuses on externalities, natural monopolies, and public goods. Akerlof (1970) explains the quality uncertainty as another source of market failure. Kaldor (1972) argues that the general economic equilibrium originally formulated by Walras and mathematically developed by Gerard Debreu is too over simplistic to depict the real world phenomena. Malkiel and Fama (1970) assembled a comprehensive review of the theory and evidence of financial market efficiency. Green (1977) discusses the non-existence of informational equilibria. Grossman and Stiglitz (1980) also model situations where a competitive equilibrium would not exist. Greenwald and Stiglitz (1986) argue that in general when risk markets are incomplete and information is imperfect, markets are not constrained Pareto optimal: the Invisible Hand does not work. In Stiglitz's words (see Stiglitz (1991)): "The Welfare Theorems are just that: theorems, the conclusions of which follow inevitably from the assumptions. The research of the last two decades has not detected any major flaws of logic. The Theorems stand, as I have said, as one of the triumphs of modern mathematical economics. The question is not the logical status of these propositions, but their empirical relevance, the inferences which we make concerning how society should be organized and about the design of economic policy. These are, to be sure, matters of judgment. The earlier analyses of market failures basically agreed with the underlying conception of the market economy that was reflected in the assumptions of the Welfare Theorems. I am not so convinced." Woodford (2002) mentions that improvements in information processing technology and deregulation, among other forces, are profoundly transforming the financial sector of the United States and other advanced economies. Many of these changes are likely to improve the efficiency of financial intermediation, in the sense that the dispersion of valuations of claims to future payments across different individuals and institutions is minimized. Ackerman, Nadal and Gallagher (2004) also call into question the assumptions in Arrow and Debreu's analysis which make the Theorems of limited relevance to modern industrial economies. Cajueiro, Gogas and Tabak (2009) assess if the financial market liberalization introduced in the beginning of the 1990s in Greece has changed the degree of market development (efficiency) by studying time-varying global Hurst exponents. Their results suggest that changes in financial market liberalization have important positive implications on the degree of development of stock markets.

There is also a huge literature discussing the efficiency of markets in the context of a society e.g., Arge and Hunt (1971) argue that for economic efficiency, what needs to be accomplished is a persuasion of the populace away from the doctrine of self-interest and toward a doctrine of cooperation and conservation. Sen (1993) argues that competitive market equilibria are weakly efficient in opportunity freedoms in terms of capabilities as well as commodity holdings. Oakley, Ashton et al. (1997) based on Titmus' famous study on paid and unpaid blood donations (1971) explains the social repercussions of creating a market for blood, inviting an un-ending debate on the issue. Frey and Oberholzer-Gee (1997) develop the argument further to show how the market mechanism for certain entities undermines an individual's sense of civic duty. Sunstein (1999) presents a new conception of the relationship between free markets and social 
justice. Folbre and Nelson (2000) elaborate that the market mechanism is unlikely to provide the quantum and quality of children, sick and elderly care. George (2004) challenges the view that free choice, as revealed by the preferences of individuals, maximizes the welfare of individuals given their income and market prices. Howell (2004) challenges the free market with regard to the labor markets around the world and persistent unemployment. Dolfsma, Finch and McMaster (2005) argue how the conceptualization of the market in relation to the society undermines the mainstream, Paretian perspective on welfare. Dolfsma (2005) highlights the importance of dynamic welfare. Satz (2010) delivers a comprehensive theory of the limits of the markets with regard to society. Hemsley-Brown (2011) portrays the challenges of a free market in higher education.

As the major focus of this paper is the efficiency on the dynamic adjustment path, it will not be out of place to acknowledge the previous literature highlighting the importance of adjustment path to equilibrium. Diamond (1971) develops a model of price adjustment assuming that firms know the demands they face. Eden (1981) explains a theory of competitive price adjustment. Hahn (1984) explains why a theory of the economy out of equilibrium is required. David (2007) emphasizes the importance of path dependence in economics. Nerlove (1958) discusses the Cobweb model which explains why prices might be subject to periodic fluctuations in certain types of markets. Cobweb model is based on adaptive expectations and subject to criticism by the advocates of rational expectations. Herings (1996) gives a price adjustment process for an exchange economy that converges generically to a Walrasian equilibrium. Tuinstra (2004) provides a price adjustment process in a model of monopolistic competition. There have been a number of ways of modeling paths to equilibrium under different set of frictions, such as incomplete markets (see Angeletos and Calvet (2005), Talman and Thijssen (2006)), adjustment costs (see Lucas (1967), Bertola and Caballero (1990), Danziger (1999) and Chen, Feng and Seshadri (2014)), rational inattention (see Chen, Levy, Ray and Bergen (2008), Ma'ckowiak and Wiederholt (2009) and Mackowiak and Wiederholt (2010)), and search costs (see Wright (1986)), etc.

The main contribution of this paper is that the commonly believed notion that if all the ideal conditions of a perfectly competitive market are maintained, the market is Pareto efficient has been challenged to the extent of dynamic adjustment path. It is shown that the market mechanism involves a huge efficiency loss during the adjustment process. It quantifies the efficiency loss on the dynamic adjustment path of a perfectly competitive financial market after an economic shock, and suggests how this efficiency level can be improved. The main source of inefficiency during the adjustment process is the agents' lack of perfect information about the exact magnitude of the shock and the new patterns of supply and demand. In the existing literature, the imperfect information generally refers to the asymmetric information among buyers and suppliers regarding the quality of a product or other factors leading to an inefficient equilibrium or the non-existence of an equilibrium. This paper shows that even though an equilibrium exists, a free financial market cannot get rid of the ineffciency on the way to the equilibrium. In a financial market, a question of asymmetric information (regarding the quality of goods, which are just funds in a financial market) does not arise. The only way a perfectly competitive financial market can be Pareto efficient during the adjustment process after an economic shock is that if all the ideal conditions of a perfectly competitive market are maintained and also if all the economic agents 
have perfect information about the exact magnitude and direction of all future shocks and the exact patterns of supply and demand in the market as a result of shocks for all times, which would have been possible only if the economic agents were God, hence making the study of economics and finance needless!

We develop a deterministic dynamic financial market model in continuous time framework. The model takes into account a supply curve, a demand curve, and an inventory curve (for funds) for the middleman/ financial intermediary. The model answers the following questions: How do the actions of three market agents, i.e., consumer, producer and the middleman/ financial intermediary in their own interest lead to the market equilibrium? Which path does the financial market follow as a result of an endogenous or exogenous shock in the steady state equilibrium? How efficient is the financial market on that path? Can a free financial market on its own minimize the efficiency losses during the adjustment process or is there any other mechanism which can help improve upon the market in terms of efficiency during the adjustment process? The model is based on mathematical formulations (in time domain) of practical behavior of key agents (without any over-simplistic assumptions) endogenously capturing the feedback effects of interest rate changes on the financial market system. A mathematical innovation in the model is the introduction of deviation variables, i.e., deviation from an equilibrium (before shock) instead of the absolute value of the variable. This makes the model free of initial conditions as the initial value of a deviation variable is always zero.

The mathematical picture provides the concrete conditions for the existence of an equilibrium which is independent of the middleman/ financial intermediary's response. This result is supported by the final steady state equilibrium (mathematical) expression which is dependent just on the responses of the consumer and the producer of funds. The parameter depicting the middleman/ financial intermediary's response drops out of the final steady state equilibrium expression. However, the mathematical analysis shows that the middleman/ financial intermediary has a very strong role in the dynamic adjustment process. The response of the middleman/ financial intermediary (along with the consumer and the producer's response) determines the adjustment path of the financial market after an economic shock. The middleman/ financial intermediary's response also determines the quantum of inefficiency during the adjustment process. The concept of dynamic efficiency has been discussed in the paper. When an economic shock hits the market, the market remains out of equilibrium during the adjustment period before it arrives at a new equilibrium. The longer the adjustment period, the greater are the efficiency losses. The market certainly cannot and does not jump to a new equilibrium (an ideal dynamic efficiency condition which is not achievable). A financial market is said to be closer to an ideal dynamically efficient state if it follows the smoothest and the shortest possible route between equilibriums after an economic shock, that is, if it minimizes the present value of output (of funds) (and/ or consumption (of funds), utility) lost. The model provides a basic framework for a dynamic welfare analysis and scope for extensions and applications in various goods, services, and labor markets.

The remainder of this paper is organized as follows: Section 2 explains how the individual components of the financial market system are joined together to form a dynamic financial market model. Section 3 provides a solution of the model in time domain. Section 4 summarizes the findings and concludes. 


\section{The model}

A perfectly competitive financial market in equilibrium is assumed (the initial point is the point of market equilibrium). Three types of infinitely-lived agents are there in the market: a representative -or a unit mass of- producer of funds (households who save and deposit the savings in banks/ financial institutions for interest payments along with the principal in return), a middleman/ financial intermediary (who purchases/ borrows the funds from producers of funds (households) to sell/ lend to consumers of funds (firms), and possibly accumulating inventories of funds), and a representative -or a unit mass of- consumer (firms who borrow funds from the financial institutions). The producer provides the funds to the middleman/ financial intermediary, who keeps an inventory of the funds and lends those to the consumer at the market interest rate. In the model, the middleman/ financial intermediary plays a key role, as he sets the selling price/ interest rate $r$ by maximizing the difference between the revenue for lending funds to consumers and the costs of inventories of funds. The buying price/ interest rate paid to the producer is $\alpha r$ with $\alpha<1$, and the producer of funds is a price taker.

The adjustment mechanism for interest rate is based on the fact that when a demand or supply shock or both lead the financial market out of equilibrium, the lenders' and borrowers' decisions at current interest rate are not coordinated. The working of this market can be illustrated by the following example: Consider the market in equilibrium. An equilibrium stock of inventory of funds is held by the middleman/ financial intermediary. An exogenous demand contraction increases the stock of inventory of funds, because the households' savings could not match with the -now lower- units of funds demanded by the firms (consumer of funds) at the current interest rate. This excess of supply is accumulated in inventory of funds held by the middleman. The middleman decreases the interest rate so that the producer of funds (household) should find optimal to supply a lower level of savings. A new equilibrium with a lower level of funds and a lower interest rate is then reached. The equilibrium in the financial market is defined as follows:

i. The middleman and the consumer of funds (firms) maximize their profits and the producer of funds (household) maximizes utility subject to the constraints they face (mentioned in Section 2 in their individual dynamic optimization problems).

ii. (ii) The quantity consumed by the consumer equals the quantity supplied by the producer (and hence the inventory of funds remain the same when the financial market is in equilibrium).

The specific conditions for the existence of the financial market equilibrium (RouthHurwitz stability criterion, which provides a necessary and sufficient condition for the stability of a linear dynamical system) have been mentioned in Section 3. When the financial market is in equilibrium, the middleman who sells/ lends the funds to the consumer at the market interest rate is a price taker as the set up is for a perfectly competitive market. The middleman can change the interest rate along the dynamic adjustment path when the financial market is out of equilibrium until the new equilibrium arrives, where again the middleman becomes a price taker. If a supply or demand shock or both hit the market, the financial market does not suddenly jump to a new equilibrium, rather the interest rate adjusts over time to bring the new equilibrium. This 
adjustment process involves endogenous decision making (in their own interest) by all the agents in the market, i.e., producer, consumer, and the middleman. For the sake of mathematical treatment, the objective of each of the three market agents is maximized subject to their respective constraints through the first order conditions of their objective functions and to get the collective outcome of their individual actions, the equations representing their individual actions are solved simultaneously. For simplification, we assume that after the shock, the new equilibrium is not too off from the initial equilibrium. This assumption justifies the linearization of demand and supply curves. In Fig. 1 (the time axis not shown), linearization seems to be a reasonable approximation when we move from point $a$ to $b$, whereas it does not seem to be a good approximation when we move from point $a$ to $c$. In order to model the movement of the financial market from point $a$ to $c$, a non-linear dynamical system must be considered (which is beyond the scope of this paper).

\subsection{Middleman/ financial intermediary}

The middleman/ financial intermediary receives deposits from the producer of funds (household) and sells/ lends those to the consumer of funds for profit. The middleman does not buy and sell exactly the same quantity of funds at all points in time, thus he/ she holds an inventory of the funds received from the producers of funds to be sold/ lent subsequently. There is an inflow and an outflow of funds. The rate of inflow cannot equal the rate of outflow all the time, as the inflow is from the producers, and the outflow is to the consumers. The producers and the consumers do not plan their decisions together, and their actions are not coordinated. The middleman/ financial intermediary accepts the funds from the producers/ households, whenever they want to deposit their funds in the financial institutions. This is practically known to us that the banks never refuse to accept our deposits, if we have an account in a bank and want to deposit our savings/ excess money with them. Similarly, the consumers request for loans according

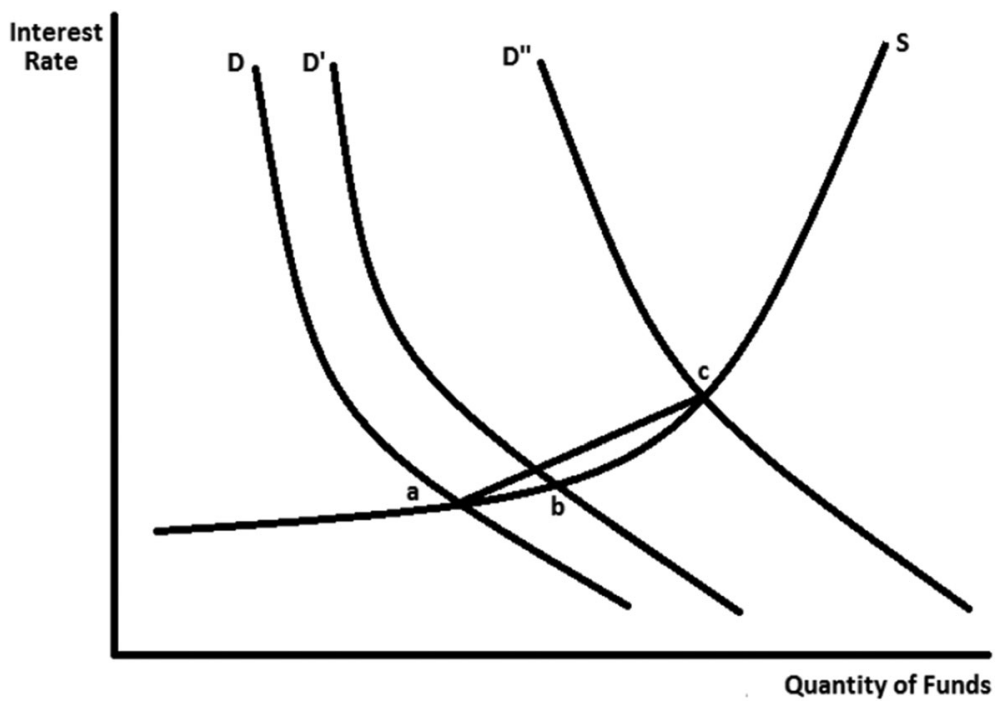

Fig. 1 When is linearity a reasonable assumption? 
to their own needs, without knowing how many deposits are available with a financial intermediary. These actions of consumers and the producers of funds are based upon their own needs which may not coincide all the time. Furthermore, when a shock, say a demand shock happens to the market, the demand contracts but the supply rate of funds does not change initially. The supply rate changes later on as a feedback, when the middleman/ financial intermediary changes the interest rate. The shocks lead either to an accumulation or a depletion of funds held by the middleman. The middleman has an opportunity cost for holding the excessive funds, this is why the middleman changes the interest rate to get rid of the excessive funds, and maximize the difference of the revenue raised through lending the funds and the cost of borrowing the funds. Inventory is an intermediary stage between supply and demand which reflects the quantum of difference between supply and demand of the funds in the financial market. If the inventory remains the same, it implies that demand and supply rates are the same. An increase or decrease in inventory implies a change in supply, demand or both at different rates.

Please look at Fig. 2 to understand the link between inventory of funds, supply, demand and interest rates. When the supply curve shifts to the right (while demand remains the same), the inventory in the market increases at the initial interest rate, and the new equilibrium brings the interest rate down. Similarly, when the demand curve shifts to the right (while supply remains constant), the inventory depletes from the market at the previous interest rate and the new equilibrium brings the interest rate up. This shows that there is an inverse relationship between an inventory change and an interest rate change (all else the same). If both the supply and demand curves shift by the same magnitude such that the inventory does not change, then the interest rate will also remain the same. Inventory unifies the supply and demand shocks in the sense that they are both affecting the same factor, i.e., inventory and are basically the faces of the same coin. Therefore, each kind of shock is in fact just an inventory shock. From the above mentioned discussion, we have seen that there is an inverse relationship between an inventory change and an interest rate change.

Now let's discuss the mechanism which brings about such a change. Consider a market of funds where the middlemen (financial intermediaries) hold inventories of funds, incur some cost for holding those, and lend funds to the consumers to make profits. The cost is a positive function of the size of an inventory of funds, i.e., a larger inventory costs more to hold as compared to a smaller inventory. In the absence of an exogenous shock, if the supply and demand rates are equal then the financial market is in equilibrium and the interest rate does not vary with time.

Suppose that an intervention decreases the marginal cost of production of funds (savings) and increases the supply rate, whereas the demand rate remains the same. As the demand and supply rates are no longer equal, therefore the difference will appear in the form of piled up funds by the financial institutions. The middlemen will have to think of some means of lending the additional funds to the borrowers (consumers). The only resort they have is to decrease the interest rate which brings the demand up along the demand curve. In a perfectly competitive market, the interest rate will eventually come down to equalize the new marginal cost, however the adjustment path depends on how the middlemen react to the change in their inventories of funds. Notice that the marginal cost of production has decreased but the marginal cost of holding an extra unit of funds for the middleman has increased. For a mathematical treatment, we need to consider the profit maximization problem of the middleman as follows: 


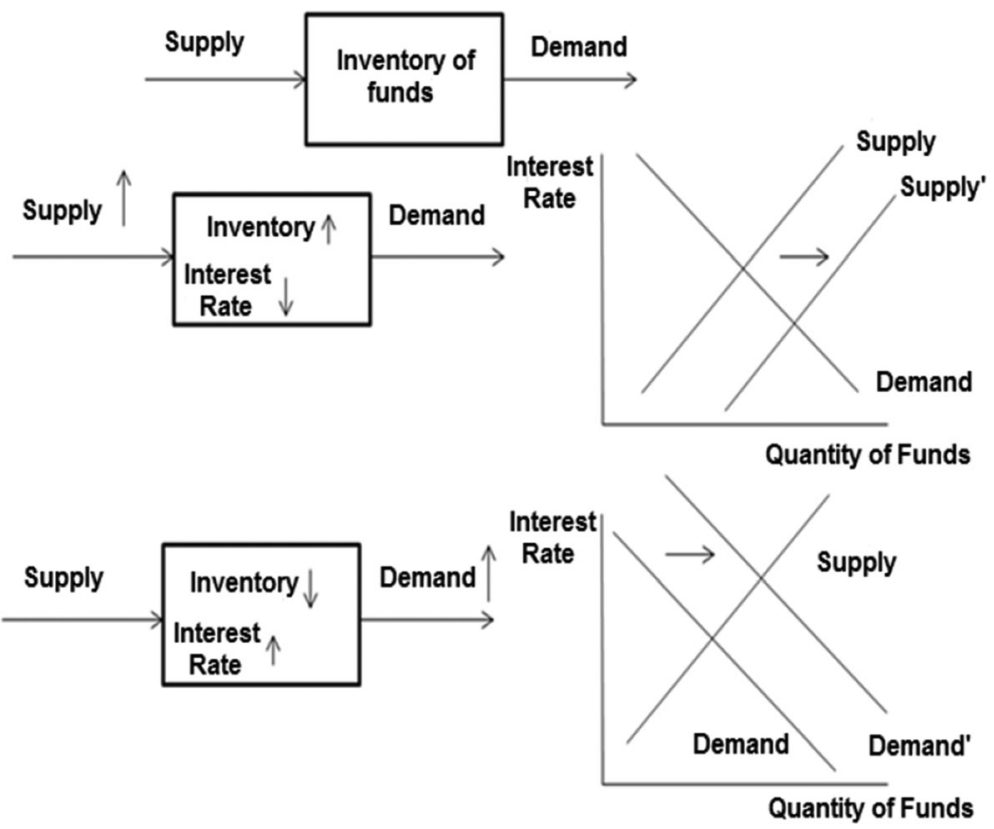

Fig. 2 Movement of interest rate with inventory of funds

\subsubsection{Static problem}

Let us first consider the static problem (Explanation: The static problem means that the middleman's objective is myopic rather than doing dynamic optimization) of the middleman as follows:

$$
\Pi=r q(r)-\varsigma(m(r, e)),
$$

where

$\Pi=$ (profit,)

$r=$ market interest rate,

$q(r)=$ quantity of funds sold (selling means lending) at interest rate $r$,

$m=$ inventory (quantity of funds held by the middleman),

$e=$ other factors which influence inventory of funds other than the market interest rate including the middleman's purchase interest rate from the producer,

$\varsigma(m(r, e))=$ cost as a function of inventory (increasing in inventory).

The first order condition (with respect to interest rate) is as follows:

$$
r q^{\prime}(r)+q(r)-\varsigma^{\prime}(m(r, e)) m_{1}^{\prime}(r, e)=0,
$$

The middleman has an incentive to change the interest rate only during the adjustment process and will incur losses by deviating from the interest rate (equal to the marginal cost) when the market is in equilibrium. During the adjustment process, the demand does not equal the supply and the market drifts toward the new equilibrium, therefore 
an interest rate change by the middleman in the direction of bringing the new equilibrium is not against the market forces, so he does not lose business by changing interest rate on the adjustment path unlike when the market is in equilibrium and where the middleman faces an infinitely elastic demand as follows:

$$
\begin{gathered}
r q^{\prime}(r)+q(r)=\varsigma^{\prime}(m(r, e)) m_{1}^{\prime}(r, e), \\
r\left[1+\frac{1}{\text { demand elasticity }}\right]=\varsigma^{\prime}(m(r, e)) \frac{m_{1}^{\prime}(r, e)}{q^{\prime}(r)} .
\end{gathered}
$$

The right hand side of the above expression is the marginal cost which equals the interest rate when the middleman faces an infinitely elastic demand. Suppose that as a result of a supply shock, the marginal cost of production of funds decreases, and the supply curve shifts downwards. Now the competitive market is out of equilibrium as the demand does not equal the supply at the previous equilibrium interest rate. The interest rate must eventually decrease to bring the new equilibrium, however, the interest rate will not jump to equalize the demand and supply, and rather the middleman will continue charging an interest rate higher than the new marginal cost until the market forces make him realize that the supply has increased and he needs to lower the interest rate to satisfy the profit maximizing condition. The similar is the case of a reverse supply shock, where the interest rate must eventually increase to bring the new equilibrium. In this case, the middleman will continue charging an interest rate lower than the marginal cost until the market forces make him increase the interest rate, in which case it is the consumer who is the short term beneficiary. Again, the consumer will be paying an interest rate less than the marginal cost only during the adjustment process and only until the middleman increases the interest rate. The equilibrium interest rate is equal to the marginal cost of production plus the marginal cost of holding funds by the financial intermediary (i.e. the total marginal cost) in the absence of any kind of a policy intervention, so neither does the middleman earn any economic rent, nor does the consumer benefit by paying an interest rate less than the marginal cost when the competitive market is in equilibrium.

For the mathematical treatment, suppose that as a result of a supply shock (while demand remains the same) which reduces the marginal cost of production of funds and increases the supply by the producer, if the middleman wants to hold an extra unit of inventory of funds, his marginal cost of holding an extra unit i.e., $\varsigma^{\prime}(m(r, e)) \frac{m_{1}^{\prime}(r, e)}{q^{\prime}(r)}$ is higher at the previous interest rate, because the term $\varsigma^{\prime}(m(r, e))$ is higher at the previous interest rate. This might be on account of higher cost of holding unutilized funds by the financial intermediary after increased supply in the market. The second term, i.e., $\frac{m_{1}^{\prime}(r, e)}{q^{\prime}(r)}$ is a function of the interest rate, and is the same as before as the interest rate has not changed yet (we are assuming that the middleman's purchase interest rate is the same as before as the producer is a price taker during the adjustment process as well and always charges a fixed fraction of the market interest rate to the middleman). A discrete analog of this scenario is that the middleman maximizes profits in each time period without considering the future time periods, and in each time period he takes the purchase 
interest rate from the producer as given and only chooses the sale (lending) interest rate. This implies that on the previous interest rate, now the middleman faces

$$
\frac{\partial \Pi}{\partial r}=r q^{\prime}(r)+q(r)-\varsigma^{\prime}(m(r, e)) m_{1}^{\prime}(r, e)<0,
$$

which means that the middleman must decrease the interest rate to hold an extra unit of inventory of funds to satisfy the profit maximizing condition after the supply shock. Please notice that in this static scenario, the short term gains accrued from the decreased marginal cost of production will be reaped by the producer, as his marginal cost has decreased but he charges the same interest rate to the middleman until the middleman changes the interest rate. If we plot together various profit maximizing combinations of inventories of funds and the respective interest rates chosen by a middleman, we will get a downward sloping inventory curve with the interest rate on the $y$-axis and the inventory of funds on the $x$-axis. This is analogous to the concept of supply and demand curves for the profit maximizing producers and the consumers of funds respectively.

\subsubsection{Dynamic problem}

Now let us consider the dynamic problem of the financial intermediary. In a dynamic setting, the financial intermediary maximizes the present discounted value of the future stream of profits, and his present value at time zero is as follows:

$$
V(0)=\int_{0}^{\infty}[r q(r)-\varsigma(m(r, e))] e^{-\sigma t} d t,
$$

$\sigma$ denotes the discount rate. $r(t)$ is the control variable and $m(t)$ the state variable. The maximization problem can be written as

$$
\underset{\{r(t)\}}{\operatorname{Max}} V(0)=\int_{0}^{\infty}[r q(r)-\varsigma(m(r, e))] e^{-\sigma t} d t
$$

subject to the constraints that.

$$
\dot{m}(t)=m_{1}^{\prime}(r(t), e(r(t), z)) \dot{r}(t)+m_{2}^{\prime}(r(t), e(r(t), z)) e_{1}^{\prime}(r(t), z) \dot{r}(t) \text { (state equation, }
$$
describing how the state variable changes with time; $z$ are exogenous factors),

$m(0)=m_{s}$ (initial condition),

$m(t) \geq 0$ (non-negativity constraint on state variable),

$m(\infty)$ free (terminal condition).

The current-value Hamiltonian for this case is

$$
\begin{aligned}
\widetilde{H}= & r(t) q(r(t))-\varsigma(m(r(t), e(r(t), z))) \\
& +\mu(t) \dot{r}(t)\left[\begin{array}{l}
m_{1}^{\prime}(r(t), e(r(t), z))+m_{2}^{\prime}(r(t), e(r(t), z)) * \\
e_{1}^{\prime}(r(t), z)
\end{array}\right] .
\end{aligned}
$$

Now the maximizing conditions are as follows: 
(i) $r^{*}(t)$ maximizes $\widetilde{H}$ for all $t: \frac{\partial \tilde{H}}{\partial r}=0$,

(ii) $\dot{\mu}-\sigma \mu=-\frac{\partial H}{\partial m}$,

(iii) $\dot{m}^{*}=\frac{\partial H}{\partial \mu}$ (this just gives back the state equation),

(iv) $\lim _{t \rightarrow \infty} \mu(t) m(t) e^{-\sigma t}=0$ (the transversality condition).

The first two conditions are as follows:

$$
\frac{\partial \widetilde{H}}{\partial r}=0
$$

and

$$
\dot{\mu}-\sigma \mu=-\frac{\partial \widetilde{H}}{\partial m}=\varsigma^{\prime}(m(r(t), e(r(t), z))) .
$$

When the market is in equilibrium, $\dot{r}(t)=0$, and the expression $\frac{\partial \widetilde{H}}{\partial r}$ boils down to the following (see appendix):

$$
\begin{aligned}
& r(t)\left[1+\frac{1}{\text { demand elasticity }}\right] \\
& \quad=\varsigma^{\prime}(m(r(t), e(r(t), z)))\left\{\frac{m_{1}^{\prime}(r(t), e(r(t), z))}{q^{\prime}(r(t))}+\frac{m_{2}^{\prime}(r(t), e(r(t), z)) e_{1}^{\prime}(r(t), z)}{q^{\prime}(r(t))}\right\},
\end{aligned}
$$

suggesting that the interest rate equals the marginal cost (the right hand side of the above expression is the marginal cost in a dynamic setting, which is different from that in a static problem on account of the fact that in a dynamic setting the middleman also takes into account the impact of interest rate chosen on his purchase interest rate from the producer) when the demand is infinitely elastic. Now suppose that as a result of a supply shock, if the middleman wants to hold an extra unit of inventory of funds, then the marginal cost of holding an extra unit is higher because the term $\varsigma^{\prime}(m(r(t), e(r(t), z)))$ is higher at the previous interest rate at that point in time. The term in parentheses in the expression of the marginal cost, i.e., $\frac{m_{1}^{\prime}(r(t), e(r(t), z))}{q^{\prime}(r(t))}+\frac{m_{2}^{\prime}(r(t), e(r(t), z)) e_{1}^{\prime}(r(t), z)}{q^{\prime}(r(t))}$ is a function of interest rate and is the same at the previous interest rate. This implies that on the previous interest rate, now the middleman faces

$$
\frac{\partial \widetilde{H}}{\partial r}<0
$$

Therefore in order to satisfy the condition of dynamic optimization, the middleman must decrease the interest rate for an increase in inventory of funds. This implies a negative relationship between interest rate and the inventory of funds. The concept of inventory unifies the market supply and demand. If the supply and demand rates are equal, the market is in a steady state equilibrium. If a difference of finite magnitude is created between the supply and demand 
rates and the consumer and the producer do not react to an interest rate change induced by a difference in the supply and demand rates, the interest rate will continue changing until the system saturates. This behavior can be depicted by the following formulation:

Interest rate change $\propto$ change in market inventory of funds.

$$
R=\text { interest rate change. }
$$

$M=m-m_{s}=$ change in inventory of funds in the market,

$$
m=\text { inventory of funds at time } t,
$$

$m_{s}=$ inventory of funds in steady state equilibrium.

$$
\begin{gathered}
\text { Input-output }=\frac{d m}{d t}=\frac{d\left(m-m_{s}\right)}{d t}=\frac{d M}{d t}, \\
\text { or } M=\int(\text { input }- \text { output }) d t .
\end{gathered}
$$

Interest rate change $\alpha$ (supply rate-demand rate $) d t$, or

$$
R=-K_{m} \int(\text { supply rate-demand rate }) d t,
$$

where $K_{m}$ is the proportionality constant. A negative sign indicates that when (supply rate-demand rate) is positive, then $R$ is negative (i.e., the interest rate decreases). The above equation can be re-arranged as follows:

$$
\begin{gathered}
\int(\text { supply rate }- \text { demand rate }) d t=-\frac{R}{K_{m}}, \text { or } \\
\int\left(w_{i}-w_{0}\right) d t=-\frac{R}{K_{m}}, \\
w_{i}=\text { supply rate, } \\
w_{0}=\text { demand rate, }
\end{gathered}
$$




$$
K_{m}=\text { dimensional constant. }
$$

Let at time $t=0$, supply rate $=$ demand rate (market is in a steady state equilibrium), then Eq. (8) can be written as.

$$
\int\left(w_{i s}-w_{0 s}\right) d t=0 \text {. }
$$

The subscript $s$ indicates the steady state equilibrium and $R=0$ in steady state. Subtracting Eq. (9) from Eq. (8), we get:

$$
\begin{gathered}
\int\left(w_{i}-w_{i s}\right) d t-\int\left(w_{0}-w_{0 s}\right) d t=-\frac{R}{K_{m}}, \text { or } \int\left(W_{i}-W_{0}\right) d t=-\frac{R}{K_{m}},(10) \\
\text { where } w_{i}-w_{i s}=W_{i}=\text { change in supply rate, } \\
w_{0}-w_{0 s}=W_{0}=\text { change in demand rate. }
\end{gathered}
$$

$R, W_{i}$ and $W_{0}$ are deviation variables, which indicate deviation from the steady state equilibrium. The initial values of the deviation variables are zero. Eq. (10) may also be written as follows:

$$
R=-K_{m} \int W d t=-K_{m} M
$$

where $W=W_{i}-W_{0}$. If $R$ gets a jump as a result of some factor other than an inventory of funds change, that is considered as a separate input and can be added to Eq. (11) as follows:

$$
R=-K_{m} \int W d t+B=-K_{m} M+B .
$$

Similarly, there can be an exogenous shock in inventory of funds other than the interest rate feedback.

\subsection{Consumer}

The consumer of funds (such as a firm seeking funds for investment) maximizes the present discounted value of the future stream of profits, and his present value at time zero is as follows:

$$
V(0)=\int_{0}^{\infty}[p(t) F(K(t), L(t))-w(t) L(t)-r(t) I(t)] e^{-\sigma t} d t
$$

$p(t)$ is the price of the output of the firm. $\sigma$ denotes the discount rate. $L(t)$ (labor) and $I(t)$ (level of investment) are the control variables and $K(t)$ the state variable. The maximization problem can be written as

$$
\underset{\{L(t), I(t)\}}{\operatorname{Max}} V(0)=\int_{0}^{\infty}[p(t) F(K(t), L(t))-w(t) L(t)-r(t) I(t)] e^{-\sigma t} d t
$$


subject to the constraints that.

$\dot{K}(t)=I(t)-\delta K(t)$ (state equation, describing how the state variable changes with time),

$K(0)=K_{0}$ (initial condition),

$K(t) \geq 0$ (non-negativity constraint on state variable),

$K(\infty)$ free (terminal condition).

The current-value Hamiltonian for this case is

$$
\widetilde{H}=p(t) F(K(t), L(t))-w(t) L(t)-r(t) I(t)+\mu(t)[I(t)-\delta K(t)]
$$

Now the maximizing conditions are as follows:

(i) $L^{*}(t)$ and $I^{*}(t)$ maximize $\widetilde{H}$ for all $t: \frac{\partial \widetilde{H}}{\partial L}=0$ and $\frac{\partial \widetilde{H}}{\partial I}=0$,

(ii) $\dot{\mu}-\sigma \mu=-\frac{\partial H}{\partial K}$,

(iii) $\dot{K}^{*}=\frac{\partial H}{\partial \mu}$ (this just gives back the state equation),

(iv) $\lim _{t \rightarrow \infty} \mu(t) K(t) e^{-\sigma t}=0$ (the transversality condition).

The first two conditions are as follows:

$$
\begin{gathered}
\frac{\partial \widetilde{H}}{\partial L}=p(t) F_{2}^{\prime}(K(t), L(t))-w(t)=0, \\
\frac{\partial \widetilde{H}}{\partial I}=-r(t)+\mu(t)=0,
\end{gathered}
$$

and

$$
\dot{\mu}-\sigma \mu=-\frac{\partial \widetilde{H}}{\partial K}=-\left[p(t) F_{1}^{\prime}(K(t), L(t))-\delta \mu(t)\right] .
$$

If the interest rate, i.e., $r(t)$ goes up, (at the previous level of investment) the firm faces

$$
-r(t)+\mu(t)<0 .
$$

Therefore in order to satisfy the condition of dynamic optimization after the interest rate increase, the firm (consumer of funds) must decrease the investment. Let the change in demand be proportional to the change in interest rate, i.e., $R$. Then we can write:

$$
\begin{gathered}
\text { Change in demand of funds } \propto R \text {, or } \\
\qquad W_{d}=-K_{d} R .
\end{gathered}
$$

$W_{d}$ is the change in demand due to $R$; when $R$ is positive $W_{d}$ is negative. 


\subsection{Producer}

The producer of funds (household) maximizes the present discounted value of the future stream of utilities, and his present value at time zero is as follows:

$$
V(0)=\int_{0}^{\infty} U(x(t)) e^{-\rho t} d t
$$

$\rho$ denotes the discount rate and $x(t)$ is the control variable. The maximization problem can be written as

$$
\underset{\{x(t)\}}{\operatorname{Max}} V(0)=\int_{0}^{\infty} U(x(t)) e^{-\rho t} d t,
$$

subject to the constraints that.

$\dot{a}(t)=r(t) a(t)+w(t)-p(t) x(t)$ (state equation, describing how the state variable changes with time). $a(t)$ is asset holdings (a state variable), and $w(t)$ and $p(t)$ are exogenous time path of wages and price of consumption $x(t)$.

$a(0)=a_{s}$ (initial condition)

$a(t) \geq 0$ (non-negativity constraint on state variable),

$a(\infty)$ free (terminal condition).

The current-value Hamiltonian for this case is

$$
\widetilde{H}=U(x(t))+\mu(t)[r(t) a(t)+w(t)-p(t) x(t)] .
$$

Now the maximizing conditions are as follows:

(i) $x^{*}(t)$ maximizes $\widetilde{H}$ for all $t: \frac{\partial \widetilde{H}}{\partial x}=0$,

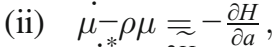

(iii) $\dot{a}^{*}=\frac{\partial H}{\partial \mu}$ (this just gives back the state equation),

(iv) $\lim _{t \rightarrow \infty} \mu(t) a(t) e^{-\rho t}=0$ (the transversality condition).

The first two conditions are as follows:

$$
\frac{\partial \widetilde{H}}{\partial x}=U^{\prime}(x(t))-\mu(t) p(t)=0
$$

and

$$
\dot{\mu}-\rho \mu=-\frac{\partial \widetilde{H}}{\partial a}=-\mu(t) r(t) .
$$

If the interest rate $r(t)$ goes up, the above maximization condition becomes as follows:

$$
\dot{\mu}-\rho \mu+\mu(t) r(t)>0
$$


Therefore in order to satisfy the conditions of dynamic optimization after the interest rate increase, the asset holdings must increase. Let $r=$ market interest rate, $c=\mathrm{a}$ reference price of assets (such as the yield on an asset which includes the cost of savings, profit of producer and profit of the financial intermediary). $c$ is a parameter which may vary with time or be kept fixed for a limited time period, e.g. the cost of savings may vary over time or can also remain constant for a while. It is the reference point with respect to which the variation in $r$ is considered by the producer of funds for decision making.

$$
W_{m}=\text { Change in production due to change in the interest rate, }
$$

$(r-c)$ acts as an incentive for the producer to provide more funds. We can write:

$$
W_{m} \propto \alpha(r-c), \text { or }
$$

$\alpha r$ is the buying interest rate paid to the producer of funds by the financial intermediary, where $\alpha<1$. The above expression can also be written as:

$$
W_{m}=K_{s}(r-c)
$$

When the market is in equilibrium, then $W_{m}=0$, or

$$
0=K_{s}\left(r_{s}-c_{s}\right)
$$

$K_{S}$ is the proportionality constant. $r_{S}$ and $c_{S}$ are the steady state equilibrium values. Subtracting Eq. (23) from Eq. (22), we get:

$$
W_{m}=K_{s}\left[\left(r-r_{s}\right)-\left(c-c_{s}\right)\right]=-K_{s}(C-R)=-K_{s} \varepsilon
$$

where $W_{m}, C$ and $R$ are deviation variables.

\section{Time domain solution with flexible interest rate and no friction}

The simplest case for the purpose of solution of the model is when the interest rate is perfectly flexible and there is no friction in the financial market, i.e. $\tau_{d 1}=\tau_{d 2}=0$. Let's solve the model for this case as follows:

From Eqs. (11) and (17) we have the following expressions:

$$
\begin{gathered}
\frac{d R(t)}{d t}=-K_{m} W(t), \\
W_{d}(t)=-K_{d} R(t), \\
W(t)=W_{i}(t)-W_{0}(t)+W_{m}(t)-W_{d}(t) \equiv W_{1}(t)-W_{d}(t) .
\end{gathered}
$$


$W_{i}(t)$ and $W_{0}(t)$ are the exogenous supply and demand rate shocks respectively. The supply shocks could be on account of changed saving patterns of people, some government regulations with respect to the interest rates, variation in income of households, etc. The demand shocks could be on account of firms' varying needs for investment, change in the price or quantity of inputs, such as labor and capital; and/ or government regulations having an impact on the demand of firms regarding funds/ deposits. We can solve the above equations simultaneously for $R(t)$ in terms of $W_{1}(t)$. Substituting $W(t)$ from Eq. (27) into Eq. (25), we get:

$$
\frac{d R(t)}{d t}=-K_{m}\left[W_{1}(t)-W_{d}(t)\right] .
$$

Now plugging Eq. (26) into the above expression, we get:

$$
\begin{aligned}
& \frac{d R(t)}{d t}=-K_{m}\left[\mathrm{~W}_{1}(t)+K_{d} R(t)\right], \text { or } \\
& \frac{d R(t)}{d t}+K_{m} K_{d} R(t)=-K_{m} W_{1}(t),
\end{aligned}
$$

where $W_{1}(t)=W_{i}(t)-W_{0}(t)+W_{m}(t) \equiv D(t)+W_{m}(t)$.

$$
D(t)=W_{i}(t)-W_{0}(t)=\text { supply rate change-demand rate change } .
$$

$D(t)$ captures the exogenous shocks. It will change either as a result of a demand shock, a supply shock or both. Now including Eq. (24) and assuming $C(t)=0$ (i.e., the production cost of funds does not change), we have the following equations:

$$
\begin{aligned}
\frac{d R(t)}{d t}+K_{m} K_{d} R(t) & =-K_{m}\left[D(t)+W_{m}(t)\right] \\
W_{m}(t) & =-K_{s} \varepsilon(t) \\
\varepsilon(t) & =-R(t) .
\end{aligned}
$$

Plugging Eq. (31) into Eq. (30) and then substituting the value of $W_{m}(t)$ into Eq. (29) we get:

$$
\begin{gathered}
\frac{d R(t)}{d t}+K_{m} K_{d} R(t)=-K_{m}\left[D(t)+K_{s} R(t)\right], \text { or } \\
\frac{d R(t)}{d t}+K_{m}\left(K_{d}+K_{s}\right) R(t)+K_{m} D(t)=0 .
\end{gathered}
$$

The Routh-Hurwitz stability criterion (which provides a necessary and sufficient condition for stability of a linear dynamical system) for the stability of the above differential 
equation is $K_{m}\left(K_{d}+K_{s}\right)>0$, which holds as $K_{m}, K_{d}$ and $K_{s}$ are all defined to be positive. This ensures that, away from a given initial equilibrium, every adjustment mechanism will lead to another equilibrium. Suppose a step input of magnitude $A$ is given to $D$.

The characteristic function of the differential equation in expression (32) is as follows:

$$
\begin{gathered}
x+K_{m}\left(K_{d}+K_{s}\right)=0, \text { or } \\
x=-K_{m}\left(K_{d}+K_{s}\right) .
\end{gathered}
$$

Thus the complementary solution is

$$
R_{c}(t)=C_{2} e^{-K_{m}\left(K_{d}+K_{s}\right) t}
$$

The particular solution has the form

$$
R_{p}(t)=C_{1}
$$

Thus the solution has the form

$$
R(t)=C_{1}+C_{2} e^{-K_{m}\left(K_{d}+K_{s}\right) t}
$$

The constant $C_{1}$ is determined by substitution into the differential equation as follows:

$$
\begin{gathered}
-K_{m}\left(K_{d}+K_{s}\right) C_{2} e^{-K_{m}\left(K_{d}+K_{s}\right) t}+K_{m}\left(K_{d}+K_{s}\right) C_{1}+K_{m}\left(K_{d}+K_{s}\right) C_{2} e^{-K_{m}\left(K_{d}+K_{s}\right) t} \\
=-K_{m} A, \\
C_{1}=\frac{-A}{K_{s}+K_{d}} .
\end{gathered}
$$

$C_{2}$ is determined by the initial condition as follows:

$$
\begin{gathered}
R(0)=\frac{-A}{K_{s}+K_{d}}+C_{2}=0, \\
C_{2}=\frac{A}{K_{s}+K_{d}} .
\end{gathered}
$$

Substituting the values of $C_{1}$ and $C_{2}$ in Eq. (33) we get:

$$
R(t)=\frac{-A}{K_{s}+K_{d}}+\frac{A}{K_{s}+K_{d}} e^{-K_{m}\left(K_{d}+K_{s}\right) t} .
$$


When $t=0, R(0)=0$ (the initial condition), and when $t=\infty$,

$$
R(\infty)=\frac{-A}{K_{s}+K_{d}}
$$

It is evident from the above expression that the final steady state equilibrium is dependent just on the responses of the consumer and the producer. The parameter, depicting the response of the middleman, i.e., $K_{m}$ dropped out of the final steady state equilibrium expression.

$D(t)$ captures both demand and supply shocks. If two or more shocks happen at the same time, e.g., if the available substitutes (or alternatives) to producers/ consumers of funds also affect the demand and supply at the same time as the initial shock, the variable $D(t)$ can capture all the demand/ supply shifts together, and Eq. (34) still remains applicable. However, if a new supply/ demand shock hits the financial market while the market is still adjusting and has not yet arrived at a new steady state equilibrium, the solution will be needing slight modification. As a result of a change or a new shock to the market before it arrives at the previously predicted (by Eq. (35)) steady state equilibrium, we will need to add a lagged input (with dead time) in $D(t)$ to arrive at the new steady state equilibrium. The adjustment path as well as the final equilibrium value will change as a result of another shock or behavioral change of agents. The model has the flexibility to cater that.

Now let's see how the response of the middleman affects the adjustment path when the interest rate is flexible and there is no friction in the financial market, that is, there is no dead time for the middleman as well as for the producer of funds (see appendix). Both these assumptions do not seem to be a depiction of the real world as the interest rate is not perfectly flexible in the short term and the producers of funds, i.e., households cannot instantaneously enhance their savings, however, the main purpose is to show that these restrictions are not vital for the main conclusion of this paper to hold, and the emphasis is on the role of the middleman/ financial intermediary which can influence the efficiency on the dynamic adjustment path even if a perfectly competitive market is free of frictions and short term interest rate rigidities. Let's consider the following three cases:

\subsection{Case $a$}

Let $K_{m}=1, K_{s}=1, K_{d}=1$ and $D(t)=A=1$, then by Eq. (34), we have

$$
R(t)=-0.5+0.5 e^{-2 t}
$$

When $t=0, R(0)=0$ (the initial condition), and when $t=\infty, R(\infty)=-0.5$ (the final steady state equilibrium value).

\subsection{Case $b$}

Let $K_{m}=2, K_{s}=1, K_{d}=1$ and $D(t)=A=1$, (please note that we just changed the value of $K_{m}$ from 1 to 2 ) then by Eq. (34), we have

$$
R(t)=-0.5+0.5 e^{-4 t} .
$$


When $t=0, R(0)=0$ (the initial condition), and when $t=\infty, R(\infty)=-0.5$ (the final steady state equilibrium value).

\subsection{Case $c$}

Let $K_{m}=4, K_{s}=1, K_{d}=1$ and $D(t)=A=1$, (please note that we just changed the value of $K_{m}$ to 4 ) then by Eq. (34)., we have

$$
R(t)=-0.5+0.5 e^{-8 t}
$$

When $t=0, R(0)=0$ (the initial condition), and when $t=\infty, R(\infty)=-0.5$ (the final steady state equilibrium value). Figure 3 depicts the dynamics of the interest rate in the financial market for all the above three cases from one equilibrium to the other after an economic shock. In all the above three cases, we got the same steady state equilibrium change, i.e., $R(\infty)=-0.5$. This is due to the fact that the responses of the producer and the consumer were kept fixed and the final steady state equilibrium depends only on their responses as shown in eq. (35). However, as we increased the value of $K_{m}$, which means changing the response of the middleman $\left(K_{m}\right.$ is the slope of the inventory curve, a large value of $K_{m}$ in absolute sense, indicates that the middleman changes the interest rate a lot for a small change in inventory), the system's adjustment path to the new steady state equilibrium changed. The vertical line in Fig. 3 is for ideal dynamic efficiency, where the financial market jumps from one equilibrium to the next. This ideal dynamic efficiency is not achievable through any practical means, however, some options are better than the others, e.g., case $c$ is the closest to the ideal dynamic efficiency as compared to the other two cases, which shows that if the middleman reacts strongly to the shock and changes the interest rate by a large magnitude for a small change in inventory (which is possible if the three economic agents have better

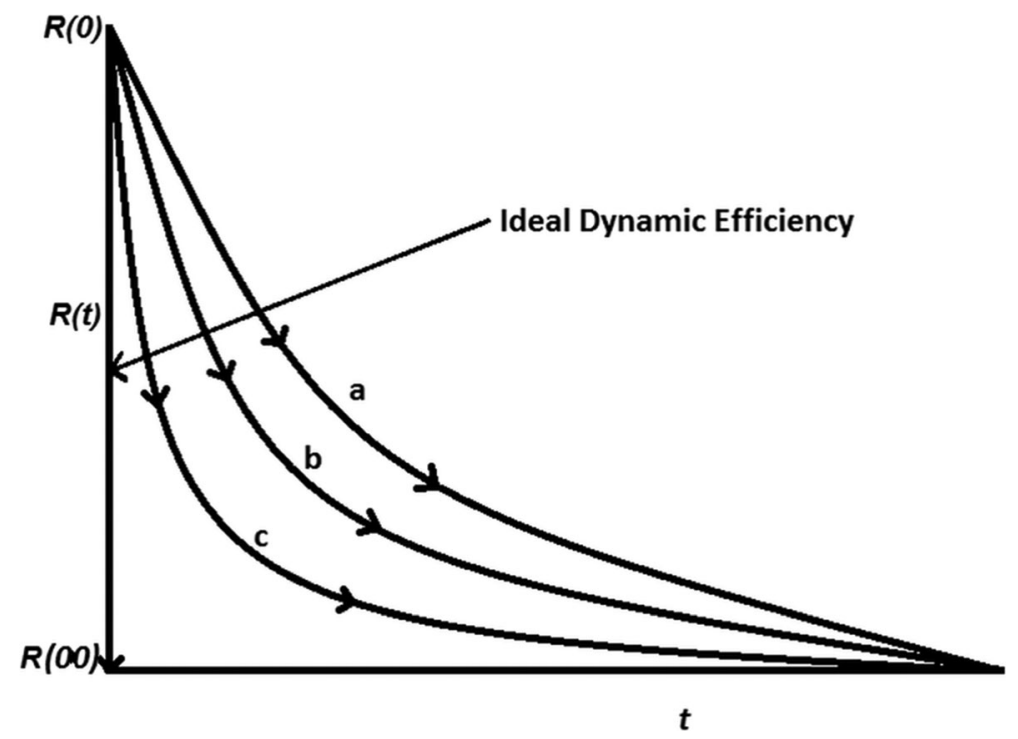

Fig. 3 Plot of $R(t)$ versus $t$ for Cases a, b and $\mathrm{c}$ 
coordination with each other), the market will quickly adjust to the new equilibrium with smaller efficiency loss.

A pile up of inventory of funds after an economic shock indicates a higher supply than demand, and a depletion of inventory occurs when demand is higher than the supply in a given time period. When the demand and supply are the same, there is no efficiency loss. If the demand and supply are different, the savings and/ or consumption of savings is being lost at that point in time. Therefore if we sum up the inventory change at all points in time during the adjustment process, we get the total efficiency loss on the dynamic adjustment path, which is as follows:

$$
E L=\int_{0}^{t}\left[W_{m}(t)-W_{d}(t)\right] d t=M(t)
$$

The area under the curves in Fig. 4 is the dynamic efficiency loss for all the three cases, which is the smallest in case $c$ (strong coordination) as compared to those for cases $a$ (free market) and $b$ (weak coordination). The characteristic function of Eq. (32) has a single root given by:

$$
x=-K_{m}\left(K_{s}+K_{d}\right)=-K .
$$

If any of the $K^{\prime} s$, i.e., $K_{s}, K_{d}$ or $K_{m}$ (the slope of the supply, demand or the inventory curve respectively) increase, the root moves on negative real axis and away from the origin, so market's adjustment to the new equilibrium becomes faster. However, it is important to notice that $K_{m}$ is being multiplied by the sum of $K_{s}$ and $K_{d}$, therefore the middleman has a stronger role on the adjustment path than that of the producer or the consumer. A higher value for any of the $K^{\prime} s$, i.e., $K_{s}, K_{d}$ or $K_{m}$ implies a stronger response on behalf of agents. A quick adjustment to the new supply-demand scenario

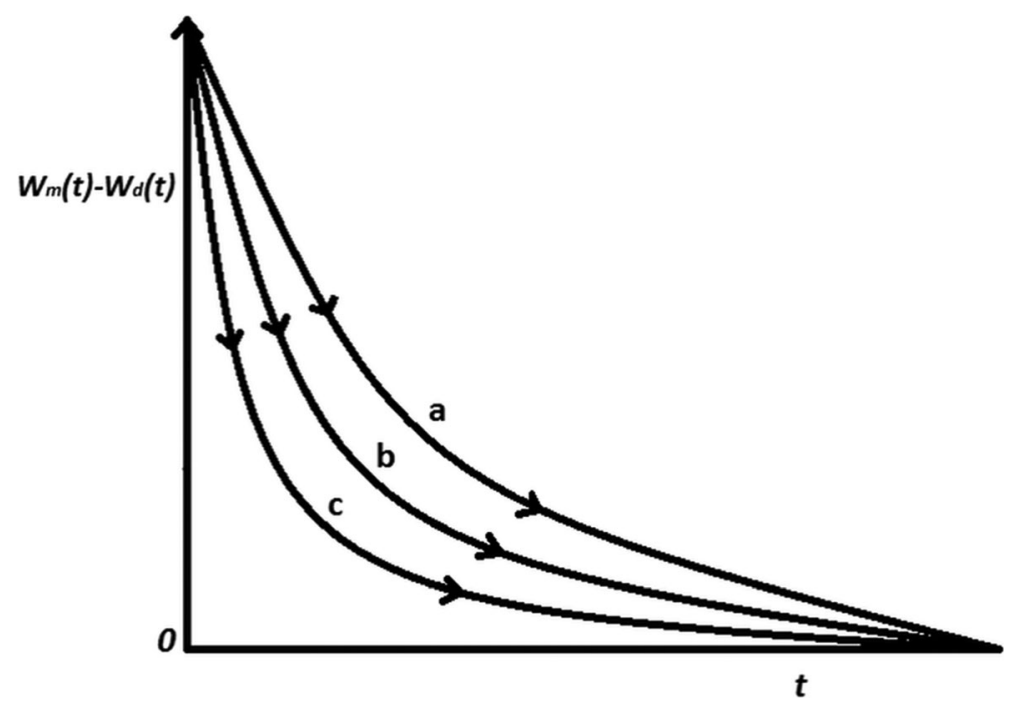

Fig. 4 Plot of $\left[W_{m}(t)-W_{d}(t)\right]$ versus $t$ for Cases a, b and c 
after the shock by agents leads to a quick adjustment of the market from one equilibrium to the other. A strong response of the middleman/ financial intermediary has a bigger impact than that of the producer and the consumer to help market adjust to the new equilibrium at a faster pace with lower efficiency loss. Coordination among the economic agents is superior to a free market in terms of economic efficiency during the adjustment of the market from one equilibrium to the other after a shock.

\section{Conclusion}

When an economic shock hits a perfectly competitive financial market, the market remains out of equilibrium during the adjustment period before it arrives at a new steady state equilibrium. The longer the adjustment period, the greater are the efficiency losses. An ideal dynamically efficient financial market would jump from one equilibrium to the other after an economic shock, and the market would always stay in equilibrium without an efficiency loss, however, this ideal situation is practically unachievable. An achievable dynamic efficiency is the smoothest and the shortest possible route which the market may adopt to move to the new steady state equilibrium after an economic shock. This path is determined by the collective action of all agents in the market, i.e., producer, middleman/ financial intermediary and the consumer. A free financial market on its own cannot minimize the efficiency loss during the adjustment process on account of lack of perfect information of the magnitude of the shock and the new patterns of supply and demand by the economic agents. However, if the agents coordinate among themselves for their economic activity, they can minimize the efficiency loss during the adjustment process.

The financial transactions between a producer and a consumer take place through the involvement of a middleman/ financial intermediary, therefore the middleman can play a significant role during the adjustment process. As, the middleman acts like a post office, the final equilibrium is determined only by the responses of the producer and the consumer as shown in Eq. (35). However, the middleman has a very strong role during the adjustment process. Suppose that after a demand shock (while supply remains the same), a consumers' representative inform the middleman about the new demand pattern of funds at various interest rates, the financial intermediary can change the interest rate much more quickly and efficiently to bring the new equilibrium as compared to that in a free market where the financial intermediary will get a signal of a demand shock only through a variation in the state of his inventory of funds (because the consumers are not obliged to inform the financial intermediary about their changed preferences), which will involve more time and efficiency loss before the adjustment to the new equilibrium takes place. Similarly if a shock happens on the supply side (while demand remains the same), the producers can lead to lower efficiency losses if they coordinate with the financial intermediary through provision of information. The incentives for coordination may vary and there can be some short term winners at the expense of others in a free market, however, coordination can certainly improve the overall economic efficiency on the adjustment path of the market to the equilibrium. As equilibrium is a short lived condition in a dynamic world where shocks happen quite frequently, efficiency during the adjustment process cannot be ignored. 
A well informed financial intermediary can take a stronger action regarding the change in interest rate as a result of a change in inventory of funds or even before an actual inventory change takes place. In all the three cases mentioned in the previous section, only the response of the middleman/ financial intermediary has been varied through the value of $K_{m}$ while the responses of the producer and the consumer have been kept fixed. The dead times for the producer and the middleman have been assigned zero values which implies flexible interest rates and no production friction (i.e., the ideal conditions of a perfectly competitive financial market are maintained). The plot for cases $a$ (free market), $b$ (weak coordination) and $c$ (strong coordination), i.e., Fig. 3 shows that the market arrives at the same new steady state equilibrium in all the three cases. However, increasing the value of $K_{m}$ (the slope of the inventory curve), which implies improved coordination among the three agents, makes the transition to the new equilibrium as short as possible, thus bringing the financial market closer to the ideal dynamically efficient system. Like all natural systems, a financial market has a self-regulation property, however it has certain limitations. In spite of an optimal behavior of the economic agents, the financial market can never achieve an ideal dynamic efficiency as depicted in Fig. 3. However, a transition path closer to the ideal situation (and practically achievable) is more desirable than others which is attainable through some coordinated action by the economic agents.

In the real world, economic shocks happen quite frequently. There can be various reasons for shocks, e.g., COVID-19 pandemic in 2019-20, availability of substitutes or alternatives, change in peoples' preferences for savings, investment, etc. The new equilibrium could either be above or below the initial equilibrium, depending upon the type (demand, supply), and the direction (expansion, contraction) of the shock. The consequence of a shock in the form of a new equilibrium ulimately can either be good or bad in terms of net efficiency gain or loss after accounting for the losses during the adjustment process.

\section{References}

Ackerman F, Nadal A, Gallagher KP (2004) The flawed foundations of general equilibrium theory: critical essays on economic theory, Routledge

Akerlof GA (1970) The market for lemons: quality uncertainty and the market mechanism. Quarterly J Econ $84: 488-500$

Angeletos G-M, Calvet L-E (2005) Incomplete-market dynamics in a neoclassical production economy. J Math Econ 41(4):407-438

Arge R, Hunt EK (1971) Environmental pollution, externalities, and conventional eco-nomic wisdom: A critique. Envtl. A 1:266

Arrow KJ, Debreu G (1954) Existence of an equilibrium for a competitive economy, Econometrica. J Econ Soci:265-290

Arrow KJ et al. (1952) An extension of the basic theorems of classical welfare economics, Cowles Commission for Research in Economics. The University of Chicago

Bator FM (1958) The anatomy of market failure. Quarterly J Econ: 351-379

Bertola G, Caballero RJ (1990) Kinked adjustment costs and aggregate dynamics, NBER macroeconomics annual 1990, vol 5. MIT press, pp 237-296

Cajueiro DO, Gogas P, Tabak BM (2009) Does financial market liberalization increase the degree of market efficiency? The case of the Athens stock exchange. Int Rev Financ Anal 18(1-2):50-57

Chen HA, Levy D, Ray S, Bergen M (2008) Asymmetric price adjustment in the small. J Monet Econ 55(4): 728-737 
Chen W, Feng Q, Seshadri S (2014) Inventory-based dynamic pricing with costly price adjustment, Production and Operations Management

Danziger L (1999). A dynamic economy with costly price adjustments. Am Econ Rev:878-901

David PA (2007) Path dependence: a foundational concept for historical social science. Clio-metrica 1(2):91114

Debreu G (1959) Theory of value: an axiomatic analysis of economic equilibrium, number 17. Yale University Press

Diamond PA (1971) A model of price adjustment. J Econ Theory 3(2):156-168

Dolfsma W (2005) Towards a dynamic (schumpeterian) welfare economics. Res Policy 34(1):69-82

Dolfsma W, Finch J, McMaster R (2005) Market and society: how do they relate, and how do they contribute to welfare? J Econ Issues:347-356

Eden B (1981) Toward a theory of competitive price adjustment. Rev Econ Stud:199-216

Folbre N, Nelson JA (2000) For love or money, or both?. J Econ Perspect:123-140

Frey BS, Oberholzer-Gee F (1997) The cost of price incentives: an empirical analysis of motivation crowdingout. Am Econ Rev:746-755

George D (2004) Preference pollution: how markets create the desires we dislike, University of Michigan Press

Green J (1977) The non-existence of informational equilibria, Rev Econ Stud:451-463

Greenwald BC, Stiglitz JE (1986) Externalities in economies with imperfect information and incomplete markets. Quart J Econ 101:229-264

Grossman SJ, Stiglitz JE (1980) On the impossibility of informationally efficient markets, The American economic review pp 393-408

Hahn F (1984) Equilibrium and macroeconomics. Blackwell, Oxford

Hemsley-Brown J (2011) Market heal thyself: the challenges of a free market in higher education. J Mark High Educ 21(2):115-132

Herings PJ-J: (1996) A globally and universally stable price adjustment process, Springer

Howell DR: (2004) Fighting unemployment: the limits of free market orthodoxy. Oxford University Press

Kaldor N (1972) The irrelevance of equilibrium economics. Econ J:1237-1255

Lucas RE (1967) Adjustment costs and the theory of supply. J Politic Econ:321-334

Mackowiak BA, Wiederholt M (2010), Business cycle dynamics under rational inattention, Citeseer

Ma'ckowiak B, Wiederholt M (2009) Optimal sticky prices under rational inattention. Am Econ Rev 99(3): $769-803$

Malkiel BG, Fama EF (1970) Efficient capital markets: a review of theory and empirical work. J Financ 25(2): 383-417

Nerlove, M.: (1958), Adaptive expectations and cobweb phenomena, Quart J Econ: 227-240

Oakley A, Ashton J et al.. (1997), The gift relationship: from human blood to social policy., London School of Economics and Political Science, (LSE)

Satz D (2010) Why some things should not be for sale: the moral limits of markets. Oxford University Press, Oxford

Sen A: (1993), Markets and freedoms: achievements and limitations of the market mechanism in promoting individual freedoms, Oxford Economic Papers 519-541

Stiglitz JE (1991) The invisible hand and modern welfare economics. Technical report, National Bureau of Economic Research

Sunstein CR (1999) Free markets and social justice, Oxford University Press

Talman A, Thijssen J (2006) Existence of equilibrium and price adjustments in a finance economy with incomplete markets. J Math Econ 42(3):255-268

Tuinstra J (2004) A price adjustment process in a model of monopolistic competition. International Game Theory Review 6(03):417-442

Woodford, M.: (2002), Financial market efficiency and the effectiveness of monetary policy

Wright, R.: (1986), Job search and cyclical unemployment, J Polit Econ:38-55

Publisher's note Springer Nature remains neutral with regard to jurisdictional claims in published maps and institutional affiliations. 